\title{
Kesehatan dan Keselamatan Kerja (K3) di Bagian Filing
}

\author{
Irmawati $^{1}$, Lily Kresnowati ${ }^{2}$, Edy Susanto ${ }^{3}$, Teni Ikhsan Nurfalah ${ }^{4}$ \\ ${ }^{1234}$ Jurusan Rekam Medis dan Informasi Kesehatan Poltekkes Kemenkes Semarang \\ Jl. Tirto Agung, Pedalangan, Banyumanik \\ 1irmachristanto@gmail.com
}

\begin{abstract}
Occupational risk can result in the decrease of work productivity, so efforts should be made to minimize the occurrence of the impact of occupational risk. Health and safety is intended to prevent, reduce, protect and even eliminate the risk of work accident (zero accident). Behavior of medical recorder filing section in work is one of the causes of risk of work accident, namely unsafe action and unsafe condition. Therefore it is necessary to conduct research on health and safety of medical records officer. To know health and safety of medical record employee of filing department at RSUD Banyumas based on human factor, work equipment factor, and work environment factor. This research type is case study with qualitative approach and cross sectional research design. The subject of this research is the medical recorder of the filing department of RSUD Banyumas while the object of the research is health and safety. Technique of collecting data by way of division of questioner, interview, observation, and study documentation. Data analysis techniques use reduction, data presentation and conclusion. The technique of data validity by means of technique triangulation. The results of this study indicate that the health and safety of medical record officer filing section seen from human factors, work equipment factors, and work environment factors. In Human Factors knowledge recorder filing Health and Safety (K3) is good enough. In environmental factors temperature and humidity are in accordance with the standard, while for lighting need to be a contrast setting light so as not too dim and too bright. On the work equipmentfactor need maintenance, repair, improvement, replacement, and addition as needed, while for shelf filing integrated mental health needs to be replaced so as not to harm filing officer.
\end{abstract}

Keywords : Occupational Health and Safety, Medical Record Officer, Human Factor, Work Environment

\begin{abstract}
Abstrak
Risiko kecelakaan kerja dapat menimbulkan turunnya produktivitas kerja, sehingga perlu dilakukan usaha untuk meminimalisasi terjadinya dampak risiko kecelakaan kerja. Kesehatan dan keselamatan kerja dimaksudkan untuk mencegah, mengurangi, melindungi bahkan menghilangkan resiko kecelakaan kerja (zero accident). Perilaku petugas rekam medis bagian filing dalam bekerja merupakan salah satu penyebab risiko terjadinya kecelakaan kerja, yaitu unsafe action dan unsafe condition. Oleh karena itu perlu dilakukan penelitian tentang kesehatan dan keselamatan kerja petugas rekam medis.Tujuan Penelitian adalah Mengetahui kesehatan dan keselamatan kerja petugas rekam medis bagian filing di RSUD Banyumas berdasarkan faktor manusia, faktor peralatan kerja, dan faktor lingkungan kerja. Jenis penelitian ini adalah penelitian deskriptif dan rancangan penelitian secara cross sectional. Subjek penelitian ini adalah petugas rekam medis bagian filing RSUD Banyumas sedangkan objek penelitiannya adalah kesehatan dan keselamatan kerja. Teknik pengambilan data dengan cara pembagian kuisioner, wawancara, observasi, dan studi dokumentasi. Teknik analisis data menggunakan editing, verifikasi organizing, analizing dan tabulasi.Hasil penelitian ini menunjukkan bahwa kesehatan dan keselamatan kerja petugas rekam medis bagian filing berdasarkan faktor manusia, peralatan kerja, dan lingkungan kerja. Pada Faktor manusia pengetahuan petugas rekam medis bagian filing menganai Kesehatan dan Keselamatan Kerja (K3) sudah cukup baik. Pada Faktor lingkungan suhu belum sesuai standar,kelembapan sudah sesuai dengan standar,sedangkan untuk pecahayan perlu adanya pengaturan kontras cahaya agar tidak terlalu redup dan terlalu terang. Pada faktor peralatan kerja perlu pemeliharaan, perbaikan, peningkatan, penggantian, dan penambahan sesuai kebutuhan ,sedangkan untuk rak filing kesehatan jiwa terpadu perlu dilakukan penggantian agar tidak membahayan petugas filing.
\end{abstract}

Kata Kunci: Kesehatan dan Keselamatan Kerja, Petugas Rekam Medis, Faktor Manusia, Faktor Lingkungan Kerja dan Faktor Peralatan Kerja. 


\section{Pendahuluan}

Rumah sakit adalah institusi pelayanan kesehatan yang menyelenggarakan pelayanan kesehatan perorangan secara paripurna yang menyediakan pelayanan rawat inap, rawat jalan dan gawat darurat (Kepmenkes No. 340 Tahun 2010).

Rekam Medis merupakan suatu dokumen, kertas (berkas) yang didalamnya mengandung tulisan tentang kenyataan, keadaan pasien selama menjalani proses perawatan pada sarana pelayanan kesehatan. Tujuan rekam medis adalah menunjang tercapainya tertib administrasi dalam rangka upaya peningkatan pelayanan kesahatan di rumah sakit.

Sistem manajemen kesehatan dan keselamatan kerja (K3) berhubungan erat dengan sistem ketenagakerjaan atau sumber daya manusia. Kesehatan dan keselamatan kerja tidak hanya penting tetapi juga dapat menunjang produktivitas kerja.

Salah satu ruang lingkup pekerjaan rekam medis adalah filing, petugas filing memiliki peran yang sangat penting dalam pelayanan kesehatan. Saat menjalankan tugasnya, petugas filing tidak bisa lepas dari potensi-potensi bahaya yang akan menyebabkan terjadinya kecelakaan kerja, contoh kecelakaan kerja dan potensi bahaya yang ada di bagian filing instalasi rekam medis antara lain kebakaran, kecelakaan instalasi listrik, terjepit lift berkas rekam medis, terjatuh pada saat mengambil berkas rekam medis, pegal-pegal, kurangnya pencahayaan dan kelembapan di ruang filing yang berdebu, dan lain sebagainya.

Berdasarkan studi di RSUD Banyumas di ruang filing dinyatakan bahwa kesehatan dan keselamatan kerja petugas rekam medis bagian filing belum mendapat perhatian yang serius sehingga dapat terjadi kecelakaan kerja. Selain itu, dari hasil wawancara yang dilakukan dengan petugas filing, diketahui bahwa petugas filing pernah hampir terjatuh dan tersayat dokumen rekam medis pada saat akan mengambil dokumen rekam medis di rak filing, hal ini disebabkan karenaketidakergonomisan sarana, rak filing dan lingkungan kerja.

\section{Metode}

Jenis penelitian yang digunakan adalah penelitian deskriptif yaitu menggambarkan hasil penelitian sesuai dengan pengamatan untuk menghasilkan gambaran sesuai dengan keadaan sebenarnya. Metode yang digunakan dalam penelitian ini adalah observasi dan wawancara dengan pendekatan cross sectional, yaitu dengan mengambil data secara langsung pada saat penelitian. Cara pengambilan data yang digunakan yaitu dengan wawancara, observasi.

\section{Hasil dan Pembahasan}

Faktor manusia (petugas rekam medis ) di ruang filing RSUDBanyumas

Faktor manusia ( petugas rekam medis ) di ruang filing RSUD Banyumas dalam penelitian ini dibagi menjadi dua faktor yaitu, karakteristik responden dan pengetahuan petugas rekam medis terkait dengan Kesehatan dan Keselamatan Kerja (K3).

\section{Karakteristik Responden}

Tabel 1: Distribusi Jenis Kelamin, Tingkat Pendidikan, Masa Kerja Dan Umur Petugas Rekam Medis Bagian FilingRSUD Banyumas Tahun 2018

\begin{tabular}{llll}
\hline No & Karakteristik responden & f & \multicolumn{1}{c}{$\%$} \\
\hline 1 & Jenis kelamin & & \\
& Laki-Laki & 7 & 58.0 \\
& Perempuan & 5 & 42.0 \\
& Total & 12 & 100.0 \\
\hline 2 & Tingkat pendidikan & & \\
& SMA & 8 & 66.6 \\
& Diploma III ( D3) & 2 & 16.7 \\
& Sarjana (S1) & 2 & 16.7 \\
& Total & 12 & 100.0 \\
\hline 3 & Masa Kerja & & \\
& s5 tahun & 3 & 25.0 \\
& 6-10 tahun & 3 & 25.0 \\
& $\geq 11$ tahun & 6 & 50.0 \\
& Total & 12 & 100.0 \\
\hline 4 & Umur & & \\
& 17-25 tahun & 4 & 33.3 \\
& 36-45 tahun & 2 & 16.6 \\
& $46-55$ tahun & 5 & 41.6 \\
& Total & 12 & 100.0 \\
\hline
\end{tabular}

Sumber : Data Primer 2018

Berdasarkan karekteristik responden pada tabel 4.1 diketahui bahwa sebagian besar jenis kelamin responden adalah laki-laki 7 orang ( $58 \%$ ) dan 5 orang perempuan ( $42 \%)$,sedangkan untuk tingkat pendidikan responden adalah SMA sebanyak 8 orang (66,6 \%), Diploma III (D3) 2 orang (16,7 \%) dan Sarjana (S1) sebanyak 2 orang (16,7\%). Masa kerja 
responden $\leq 5$ tahunsebanyak 3 orang $(25 \%), 6-10$ tahun sebanyak 3 orang $(25 \%)$ dan $\geq 11$ tahun ada 6 orang $(50 \%)$,kemudian umur responden untuk kategori remaja akhir (17-25 tahun) ada 4 orang $(33,3 \%)$,kategori dewasa akhir ( 36-45 tahun ) terdapat 2 orang $(16.6 \%)$ dan untuk kategori lansia awal (46-55 tahun) terdapat 5 orang $(41,6 \%)$

Pengetahuan petugas rekam medis bagian filing terkait dengan Kesehatan dan Keselamatan Kerja (K3).

Tabel 2: Pengukuran pengetahuan petugas rekam medis bagian filing tentang kesehatan dan keselamatan kerja (K3)RSUD Banyumas Tahun 2018

\begin{tabular}{llll}
\hline No & Pengetahuan & Jumlah & Prosentase \% \\
\hline 1 & Baik & 11 & 91,6 \\
2 & cukup & 1 & 8,3 \\
3 & kurang & 0 & 0 \\
\hline Total & & 12 & 100 \\
\hline
\end{tabular}

Sumber : Data Primer 2018

Dari jawaban responden yang didapat dari kuisioner apabila dibandingkan dengan teori dapat diketahui bahwa pengetahuan petugas rekam medis bagian filing tentang prosedur kerja terkait $\mathrm{K} 3$ di rumah sakit sudah baik. Karena sebanyak 11 orang $(91,6 \%)$ berpengetahuan baik. Selain itu ada 1 orang $(8,3 \%)$ mempunyai pengetahuan cukup.

Faktor lingkungan kerja di ruang filing RSUD Banyumas Pencahayan

Tabel 3 Pengukuran Tingkat Pencahayaan di Ruang Filing RSUD Banyumas Tahun 2018

\begin{tabular}{|c|c|c|c|c|c|c|c|}
\hline \multirow{2}{*}{ Ruang } & & \multicolumn{5}{|c|}{ Titik pengukuran ( luxI) } & \multirow{2}{*}{$\begin{array}{c}\text { Rata- } \\
\text { rata }\end{array}$} \\
\hline & & P1 & $\mathbf{P 2}$ & P3 & P4 & P5 & \\
\hline Ruang & A & 20 & 27 & 36 & 14 & 24 & \\
\hline filing & B & 19 & 30 & 38 & 4 & 15 & 31 \\
\hline umum & $\mathrm{C}$ & 60 & 47 & 42 & 58 & 31 & \\
\hline $\begin{array}{l}\text { Ruang } \\
\text { filing } \\
\text { kesehatan } \\
\text { jiwa } \\
\text { terpadu }\end{array}$ & $\mathrm{D}$ & 2050 & 223 & 222 & 134 & 35 & 595,8 \\
\hline
\end{tabular}

Berdasarkan hasil penelitian yang di dapat bahwa pencahyaan yang ada di filing umum didapatkan hasil 31 luks. Nilai ini masih sangat kurang bila dibandingkan dengan teori yang ada sehingga dapat menyebabkan kelelahan mata, berkurangnya daya dan efisiensi kerja. Hal ini justru berbanding terbalik dengan pencahayaan yang ada di ruang filing kesehatan jiwa terpadu yang bernilai 595,8 luks, yang artinya bahwa penerangan di ruang filing kesehatan jiwa terpadu melebihi standar yang seharusnya sehingga dapat juga menyebabkan kelelahan mata, berkurangnya daya dan efisiensi kerja ,kelelahan mental, keluhan-keluhan pegal di daerah mata dan sakit kepala sekitar mata, kerusakan alat penglihatan, meningkatnya kecelakaan kerja.

\section{Suhu/Temperatur di ruang filing}

Tabel 4. Hasil pengukuran suhu ruang filingRSUD Banyumas Tahun 2018

\begin{tabular}{|c|c|c|c|c|}
\hline \multirow[t]{2}{*}{ Ruang } & & \multicolumn{2}{|c|}{$\begin{array}{l}\text { Titik } \\
\text { pengukuran } \\
(0 \mathrm{C})\end{array}$} & \multirow[t]{2}{*}{$\begin{array}{l}\text { Rata } \\
\text {-rata } \\
-(0 \mathrm{C})\end{array}$} \\
\hline & & P1 & $\mathrm{P} 2$ & \\
\hline \multirow{3}{*}{ Ruang filing umum } & A & 27,8 & 28 & \multirow{3}{*}{27,6} \\
\hline & B & 27,8 & 27,4 & \\
\hline & $\mathrm{C}$ & 27,3 & 27,5 & \\
\hline $\begin{array}{l}\text { Ruang filing } \\
\text { kesehatan jiwa } \\
\text { terpadu }\end{array}$ & $\mathrm{D}$ & 27,6 & 27,4 & 27,5 \\
\hline
\end{tabular}

Sumber : Data Primer 2018

Ruangan penyimpanan arsip jangan terlalu lembab, harus dijaga supaya tetap kering. Supaya ruangan tidak terlalu lembab perlu diatur berkisar $65^{\circ} \mathrm{F}$ sampai $75^{\circ} \mathrm{F}$ atau $22^{\circ} \mathrm{C}$ sampai $25^{\circ} \mathrm{C}$ dan kelembapan udara sekitar 50\% sampai 65\%. (Depkes,1997). Produktivitas kerja manusia akan mencapai tingkat yang paling tinggi pada temperatur sekitar 24 derajat Celcius sampai 27 derajat Celcius.(Wignjosoebroto,2000). Dari hasil oebservasi jika dibandingkan dengan teori suhu di ruang filing umum bernilai 27,6 derajat celcius, suhu tersebut belum sesuai dengan standar yang ada, meskipun sudah adanya AC di ruang filing umum. Suhu yang ada di ruang filing kesehatan jiwa terpadu bernilai 27,5 derajat celcius nilai ini juga belum sesuai standar meskipun sudah terdapat AC .

\section{Kelembapan}

Tabel 5: Hasil pengukuran kelembapan diruang filingRSUD Banyumas Tahun 2018

\begin{tabular}{lllll}
\hline \multirow{2}{*}{ Ruang } & \multicolumn{3}{l}{$\begin{array}{l}\text { Titik pengukuran } \\
(\%)\end{array}$} & \begin{tabular}{l} 
Rata \\
-rata \\
\cline { 2 - 4 }
\end{tabular} \\
\cline { 2 - 4 } & P1 & P2 & \\
\hline \multirow{3}{*}{ Ruang filing umum } & 68 & 67 & \\
& B & 65 & 65 & 65,5 \\
& C & 65 & 65 & \\
\hline
\end{tabular}




\begin{tabular}{lllll}
\hline \multirow{2}{*}{ Ruang } & \multicolumn{3}{l}{$\begin{array}{l}\text { Titik pengukuran } \\
(\%)\end{array}$} & $\begin{array}{l}\text { Rata } \\
\text {-rata }\end{array}$ \\
\cline { 2 - 3 }$(\%)$ & P1 & P2 & 68 \\
\hline $\begin{array}{l}\text { Ruang filing } \\
\text { kesehatan jiwa } \\
\text { terpadu }\end{array}$ & D & 67 & 69 & 68 \\
\hline
\end{tabular}

Sumber : Data Primer 2018

Standar kelembapan di tempat kerja adalah 65\% 95\%. (Sedarmayanti ,1996). Dari hasil observasi jika dibandingkan dengan teori kelembapan di ruang filingumum bernilai 65,6 \% sehingga dapat disimpulkan bahwa kelembapan di ruang filing umum sudah sesuai standar yang di ada, Sedangkan kelembapan di ruang filing kesehatan jiwa bernilai $68 \%$ yang artinya juga sudah sesuai standar yang ada yaitu diantara $65 \%-95 \%$.

\section{Faktor Peralatan kerja di ruang Filing RSUD Banyumas}

\section{Pemeliharaan dan Perbaikan Peralatan Kerja di Ruang Filing}

Pemeliharaan yang dimaksud adalah perawatan terhadap perlengkapan materiil dengan tujuan agar perlengkapan dapat lebih awet (mengurangi kecepatan rusak). Pemeliharaan lebih ditekankan pada pencegahan sebelum terlanjur rusak, dengan pertimbangan biaya yang lebih ringan. Faktor kedua dari peralatan kerja adalah perbaikan atau reparasi. Reparasi adalah perbaikan terhadap perlengkapan materiil, agar dapat berfungsi sebagaimana mestinya. (Sedarmayanti 1996),

Dari hasil penelitian tentang pemeliharaan peralatan kerja apabila dibandingkan dengan teori dapat diketahui bahwa pemeliharaan peralatan kerja di ruang filing belum dilaksanakan secara rutin sehingga mempercepat kerusakan pada peralatan kerja. Peralatan kerja yang mengalami kerusakan menimbulkan risiko kecelakaan kerja yang lebih tinggi.

Dari hasil penelitian tentang perbaikan peralatan kerja apabila dibandingkan dengan teori dapat diketahui bahwa perbaikan peralatan kerja dilaksanakan jika ada keluhan atau laporan kerusakan. Perbaikan dilakukan agar peralatan kerja yang rusak dapat berfungsi seperti semula. Perbaikan dilakukan agar dapat mengoptimalkan produktivitas kerja dan menjaga kesehatan dan keselamatan kerja petugas rekam medis. Menurut Santoso dan Sugiarsi(2017) instrumen yang digunakan dalam pelaksanaan monitoring atau riview manajemen risiko ini adalah berupa laporan internal mengenai insiden risiko yang terjadi di unit filing.Monitoring manajemen risiko dilakukan setiap sebulan sekali melalui rapat rutin unit rekam medis dan terkadang dilaksanakan setiap waktu saat insiden tertentu dan yang dibahas dalam rapat atau riview tersebut mengenai masalah risiko dan kendala yang sudah terjadi di unit filing. Dan dari hasil rapat evaluasi tersebut biasanya menghasilkan sebuah solusi mengenai masalah manajemen risiko dan bahkan kebijakan atau aturan baru.

\section{Peningkatan Kualitas, Penggantian, dan Penambahan Peralatan Kerja di Ruang Filing}

Peningkatan adalah mengusahakan perlengkapan materiil pada kondisi yang lebih baik sehingga umur dan nilainya akan bertambah. Penggantian adalah mengganti perlengkapan yang telah ada dengan perlengkapan lain yang lebih sesuai. Sedangkan, penambahan adalah penambahan jumlah perlengkapan yang fungsinya sama, sehingga nilai total dari perlengkapan yang sejenis akan bertambah. (Sedarmayanti ,1996)

Apabila hasil penelitian tentang peningkatan dibandingkan dengan teori maka dapat diketahui bahwa peningkatan kualitas peralatan kerja di ruang filing belum dilaksanakan karena minimnya anggaran dan mengoptimalkan peralatan kerja yang ada selama masih dapat digunakan. Peralatan kerja yang digunakan menggunakan kualitas standar sehingga dalam penggunaannya masih dapat digunakan selama belum rusak. Namun, beberapa rak penyimpanan dilakukan peningkatan kualitas dengan penggantian bahan dari kayu menjadi besi agar lebih kuat.

Dari hasil penelitian tentang penggantian dengan teori dapat diketahui bahwa penggantian peralatan kerja yang rusak telah dilakukan. Namun dalam pelaksanaan penggantian harus menunggu persetujuan dari IPSRS. Misalnya pada kerusakan AC di ruang filing, dari pihak instalasi rekam medis meminta penggantian karena AC kurang dingin sehingga menimbulkan suhu ruangan menjadi panas. Namun penggantian AC tidak dilakukan karena AC masih bisa diperbaiki.

Apabila hasil penelitian tentang penambahan dibandingkan dengan teori maka dapat diketahui bahwa penambahan peralatan kerja telah dilakukan. Penambahan dilakukan apabila kebutuhan peralatan kerja benar-benar diperlukan. Misalnya penambahan rak penyimpanan mengingat semakin banyak pasien baru sehingga berkas rekam medis semakin 
banyak. Penggunaan rak penyimpanan yang terlalu penuh dapat mengakibat rak roboh atau ambruk dan menyulitkan petugas rekam medis bagian filing kesulitan dalam bekerja. Oleh karena itu, perlu adanya penambahan rak penyimpanan.

\section{Kondisi Rak Penyimpanan di Ruang Filing}

Ukuran rak diatur sedemikian rupa sehingga petugas penyimpanan tidak perlu memanjat bila akan mencari berkas rekam medis. Usahakan agar tinggi rak tidak melampaui jangkauan tangan manusia sehingga untuk mencari berkas rekam medis petugas perlu ditopang atau memanjat karena tingginya rak penyimpanan berkas bisa terjangkau oleh tangan manusia .(Martono ,1990).

Dari data anthropometri untuk orang Indonesia, tinggi jangkauan keatas diukur dari luar ujung jari tengah sampai denganalas kaki dalam keadaan berdiri adalah 202,01 cm.(Wignjosoebroto ,2000)

Dari hasil penelitian apabila dibandingkan dengan teori dapat diketahui bahwa untuk rak filing untuk filing umum sudah sesuai standar, karena telah menggunakan Roll,O Pack dengan tinggi rak $200 \mathrm{~cm}$. Sedangkan untuk rata-rata jangkauan tinggi petugas rekam medis dibagian filing umum adalah $202,5 \mathrm{~cm}$. Hal ini menujukkan bahwa tinggi rak filing di filing umum tidak lebih tinggi daripada jangkuan, sehingga dapat disimpulkan bahwa rak filing untuk rak filing umum sudah ergonomis. Kemudian untuk rak filing di filing kesehatan jiwa terpadu masih menggunakan rak yang terbuat dari besi dan kayu dengan tinggi mencapai $350 \mathrm{~cm}$ sedangkan tinggi rata-rata jangkauan petugas rekam medis di bagian filing kesehatan jiwa terpadu adalah $205 \mathrm{~cm}$. Perbedaan terpaut jauh antara tinggi rak dan jangkauan tinggi rata rata petugas rekam medis di filing kesehatan jiwa terpadu. Hal ini menyebabkan petugas harus menggunakan alat bantu berupa tangga lipat untuk menjangkau berkas rekam medis paling tinggi. Penggunaan tangga lipat ini meningkatkan resiko terjatuh bagi petugas. Menurut Santoso dan Sugiarsi (2017) Faktor risiko ergonomi merupakan faktor risiko yang paling kelihatan di unit filing, dikarenakan tinggi rak filing kurang lebih 3,25 meter. Resiko yang mengkin timbul antara lain adalah petugas terjatuh. Upaya pengendaliannya yaitu digunakannya tangga alumunium dalam mengambil dan menjajarkan dokumen rekam medis.

\section{Simpulan}

Pencahayaan di ruang filing umum masih sangat kurang sehingga perlu ditambah lampu agar ruangan lebih terang. Sedangkan pencahayandi ruang filing kesehatan jiwa terpadu justru sangat berlebihan.

\section{Daftar Pustaka}

Azimah, H.U. (2013). Tinjuan Kesehatan dan Keselamatan Kerja di bagian filing RSUD Kota Semarang Tahun 2013 (Karya Tulis Ilmiah). Semarang: Program Studi DIII Rekam Medis dan Informasi Kesehatan, Fakultas Kesehatan Universitas Dian Nuswantoro Semarang.

Ervianto, W. (2005). Manajemen Proyek Konstruksi (Edisi revisi). Yogyakarta: Andi.

Hasibuan, M.S.P. (2003). Manajemen Sumber Daya Manusia (Edisi Revisi). Jakarta: Bumi Aksara.

Huffman, E.K. (1994). Health Information Management. Physician Record Company: Berwyn Illinois.

Kementerian Kesehatan Republik Indonesia. (2010). Keputusan Menteri Kesehatan Republik Indonesia Nomor 340 Tahun 2010 tentang Klasifikasi Rumah Sakit. Jakarta: Pemerintah.

Kementerian Kesehatan Republik Indonesia. (2008). Keputusan Menteri Kesehatan Republik Indonesia Nomor 269 Tahun 2008 tentang Rekam Medis. Jakarta: Pemerintah.

Kuswana, W.S. (2014). Ergonomi dan K3. Bandung: PT Remaja Rosdakarya Offset.

Martono, E. (1990). Record Manajemen dan Filing Dalam Praktek Perkantoran Modern. Jakarta: Karya Utama

Notoatmodjo, S. 2003. Pendidikan Perilaku Kesehatan. Jakarta: PT. Rineka Cipt

Santoso, AB, Sugiarsi S.2017. Tinjauan Penerapan Manajemen Risiko Di Unit Filing Rsud Dr. Moewardi. Jurnal Manajemen Informasi Kesehatan Indonesia(JMIKI) Vol 5 No 2.

Siagian, S. 2003. Kiat Meningkatkan Produktivitas Kerja. Jakarta : Bina Aksara.

Savitri, C. (2011). Manajemen Unit Rekam Medis. Yogyakarta: Quantum Sinergis Media.

Soemirat, J. (2000). Epidemiologi Lingkungan. Yogyakarta: Gajah Mada University Press. 